\title{
Actores sociales, redes de negocios y corporaciones en Hispanoamérica, siglo XVII-XIX
}

\section{Matilde Souto Mantecón}

Instituto de Investigaciones Dr. José María Luis Mora, México msouto@mora.edu.mx

Antonio Ibarra, Álvaro Alcántara y Fernando Jumar (coords.), Actores sociales, redes de negocios y corporaciones en Hispanoamérica, siglo XVII-XIX, México, UNAM-Facultad de Economía / Bonilla Artigas Editores, 2019.

Este libro tiene una estructura muy interesante que no sé si es intencional o se dio espontáneamente. Está dividido en tres partes, cada una precedida por un ensayo escrito por una figura sobresaliente de la historiografía económica y social en las que aplican las perspectivas de las historias relacional y global. A su vez, cada una de las partes de este libro incluye una sección temática integrada por tres ensayos que tienen tres ejes comunes: los actores de los procesos históricos, las redes que ellos forjaron y las corporaciones que construyeron, tres ejes casi todos analizados mediante métodos de las historias relacional y global. Se trata, pues, de un libro con doce ensayos en el que todo está organizado en tríadas: tres son los coordinadores de la obra, que está compuesta por tres partes, cada una integrada por tres trabajos temáticos articulados a partir de tres grandes temáticas encabezadas por tres ensayos metodológicos.

\section{(c) (7) (9)}

Esta obra está protegida bajo una Licencia Creative Commons AtribuciónNo-Comercial 4.0 Internacional.

Secuencia. E-ISSN 2395-8464

http://secuencia.mora.edu.mx/

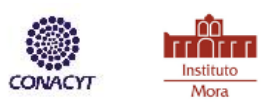


Independientemente de la estructura, se trata de una obra singular en la medida en la que desde la introducción, Álvaro Alcántara y Antonio Ibarra establecen de manera clara y precisa los principios historiográficos que guían este esfuerzo colectivo. De entrada, pues, este libro tiene un valor doble, pues se trata de una obra dedicada específicamente al estudio de los actores sociales, las redes de negocios y las corporaciones hispanoamericanas de los siglos XVII a XIX, pero también es una obra que explícitamente se ubica en el debate historiográfico del temprano XXI. Alcántara e Ibarra observan el giro que han tenido los estudios al prestar atención a las acciones individuales y las relaciones sociales efectivas al modo de la microhistoria y de las redes sociales, que aplicadas a la economía han avanzado de manera sostenida en el conocimiento del mundo de los negocios, los nexos comerciales y la construcción de distintas escalas del poder en el imperio español. Pero no se trata sólo del giro historiográfico en el que el foco de la atención se ha desplazado de la estructura a la agencia de los actores sociales individuales y colectivos, sino que también la transformación historiográfica se debe al uso de escalas espaciales diversas que van desde lo local a lo global.

La atención que presta este esfuerzo colectivo a su posición en la historiografía queda en claro en los tres ensayos que encabezan cada una de las partes que integran el libro, pues son reflexiones metodológicas sobre los análisis relacionales, el uso de las distintas escalas, el empleo de las fuentes y la adecuación de los conceptos en función de la evidencia empírica.

El primero de estos ensayos está escrito por José María Imízcoz. Parte por definir lo que para él es la historia global y cito: "la voluntad por superar las historias nacionales y el relato tradicional de la modernidad occidental, para privilegiar un enfoque mundial que observe los fenómenos trasnacionales en todos los órdenes, económicos, políticos, culturales, tecnológicos, que los compare a escala global y que analice los procesos de divergencia y convergencia entre las diferentes regiones del mundo”. Destaca así la interdisciplinariedad y Secuencia. E-ISSN 2395-8464 
la combinación de diversas escalas de espacio y tiempo, pero advierte que la clave para alcanzar la dimensión global es realizar un "análisis relacional”, es decir, un análisis inductivo a partir de los actores sociales. Sólo así, señala Imízcoz, se podrá trascender una historia global plana, limitada por su carácter comparativo, a una verdadera historia conectada a nivel global. Insiste además en la recuperación de la historia diacrónica para reconstruir los cambios a lo largo del tiempo y se decanta por la historia conectada analizada a partir de la construcción de redes egocentradas. Imízcoz discute sobre todo con la Global History anglosajona -pero en este punto llama la atención que no cita explícitamente a ninguno de los autores que la han desarrollado, pues se basa sobre todo en sus propias reflexiones y experiencias y en la historiografía francesa.

El ensayo de Imízcoz que acabamos de reseñar encabeza la primera parte del libro titulada "De la red social al análisis relacional” cuya sección temática trata de los "Actores sociales y el orden relacional en el Antiguo Régimen Hispanoamericano”. Esta sección está compuesta por tres ensayos escritos respectivamente por Sergio Tonatiuh Serrano, Álvaro Alcántara y Karina del Rocío Mota. Los tres coinciden en analizar la convergencia de las escalas local y global. Serrano Hernández se propuso estudiar cómo las minas de San Luis Potosí se integraron en el siglo XVII en la llamada primera globalización de la economía. Aunque en este trabajo sólo reconstruyó la red generada por el flujo de minerales hacia la ciudad de México, planteó la hipótesis de sus futuras investigaciones: la conexión de las minas de San Luis Potosí con la red de comercio en el Atlántico manejada por los cripto-judíos portugueses.

El segundo de los ensayos temáticos fue escrito por Álvaro Alcántara sobre las trayectorias familiares de la costa de Sotavento en el último tercio del XVIII. Es interesante cómo invirtió el enfoque usual y desarrolló su análisis de abajo hacia arriba, de lo local a lo regional e imperial. Partió de una intensa revisión de documentación primaria que le permitió Secuencia. E-ISSN 2395-8464 
seguir el derrotero de los actores sociales ubicados en pequeñas localidades del Sotavento para reconstruir sus vínculos, alianzas y conflictos de allí hacia otras regiones de Nueva España. Esto le permitió ocuparse de personajes no siempre atendidos, como los mulatos e indios, eslabones locales de una cadena de producción y comercio con un largo alcance. Alcántara comparte la idea de que su actuación económica es sólo una faceta indisociable de otras, como la política y la social, e insiste con acierto en la multiplicidad de identidades socio-profesionales que un mismo sujeto encarna.

Karina Mota en el tercer ensayo temático de esta sección trata de los grupos de poder en Guadalajara en un periodo interesante, pues los rastrea desde el último cuarto del siglo XVIII hasta los años treinta del XIX. En este trabajo se propuso presentar un esbozo de la dinámica relacional de la élite y de las cualidades de los grupos de poder de la Guadalajara centrándose en su riqueza y su permanencia a lo largo del tiempo. Ella también plantea la identificación de lo político y lo económico de sus actores, pero percibe una transformación muy interesante ocurrida en el XIX, cuando observa que la élite se dividió y una rama mantuvo claramente el poder político y la otra el económico, a diferencia de lo ocurrido al final del XVIII cuando una sola oligarquía acaparaba ambas esferas, asunto que promete y debe demostrar en futuras investigaciones, pues no es lo que usualmente se ha planteado.

La segunda parte del libro comienza con el ensayo metodológicos escrito por Zacarías Moutoukias. Inicia cuestionando la relación entre las historias conectadas y la globalización porque, según parece desprenderse de los primeros párrafos de su texto, concibe la globalización medida en función de la integración de los mercados. Pero inmediatamente aclara que ese no es su interés, sino que busca estudiar la globalización -y en este punto aclara que se referirá a la globalización arcaica- con las herramientas de la microhistoria. Es decir, que su objetivo es reflexionar sobre las redes sociales en su doble vertiente como objeto y Secuencia. E-ISSN 2395-8464 
como herramienta de estudio en el Antiguo Régimen. En su planteamiento Moutoukias sí hace un contrapunto entre varios autores que han marcado el nuevo giro historiográfico de las historias global y de contactos, como Conrad, Bayly, Flynn y Giráldez, O’Rourke y Williamson, Gruzinski y Subrahmanyam. Pero él, Moutoukias, pone en el centro de su análisis el ámbito de lo político y busca mediante los análisis relacionales, principalmente el de redes sociales, resaltar las conexiones políticas y económicas de los actores sociales. Moutoukias cierra su ensayo con una reflexión importante acerca de la centralidad de la dimensión política en la globalización arcaica. Cito: "No tiene sentido preguntarse si los mercados estaban más o menos integrados. Estos actores estaban conectados y circulaban con las reglas de las instituciones en que vivían. La globalización que comenzó a mediados del siglo XIX fue internacional. Y la nación es otro mundo”.

Esta segunda parte del libro titulada "Mercados y actores en la economía global del Imperio Hispanoamericano", formado por una sección temática sobre los "Espacios mercantiles, actores colectivos y los negocios en el Imperio Hispanoamericano”, incluye tres ensayos escritos por Fernando Jumar, Yovana Celaya y Antonio Ibarra. El trabajo de Jumar es una síntesis de preguntas, hipótesis y avances de investigación -suyos y de otros investigadoressobre el sistema de dominación que se estableció en Hispanoamérica en la Modernidad, en particular siguiendo un eje concreto: la circulación mercantil, en la que confluyen la producción y los mercados tanto como los actores y las instituciones que le dieron vida. Discípulo confeso de Carlos Sempat Assadourian, Jumar se propone sin embargo trascender el paradigma nacional-colonial al expandir la mirada del interior de las economías americanas hacia el exterior del continente.

Yovana Celaya dedica su estudio a los "Negocios, comerciantes y redes entre Puebla y Xalapa en el siglo XVIII”. Con base en el análisis de los registros notariales de ambas ciudades, Secuencia. E-ISSN 2395-8464 
Celaya estudia las estrategias de negocios del grupo que constituyó una Junta de Diputados del Comercio. Destaca el binomio que las dos ciudades formaron, ya que Puebla fue para los xalapeños un mercado de consumo y fuente para obtener préstamos de la comunidad eclesiástica. Celaya emprende su investigación desde Puebla reconstruyendo los flujos de intercambio hacia Xalapa, lo que le permite identificar a los comerciantes que formarían la Junta que representaría y defendería sus intereses mercantiles.

Antonio Ibarra es el autor del tercer ensayo de esta sección temática. Su trabajo "Redes de negocios y actores corporativos: del espacio local al mundo global en la Guadalajara colonial” muestra cómo las relaciones interpersonales dentro de las corporaciones permitieron obtener recursos y ganar certidumbre en los negocios. Con un cuidadoso y elaborado análisis de redes ego-centradas, Ibarra reconstruye detalladamente las variadas relaciones interpersonales y ofrece su imagen visual, con lo que consigue hacer una nueva descripción.

La tercera parte del este libro, titulada "Corporaciones, poder y negocios en el espacio Hispanoamericano”, comienza con un ensayo metodológico a cargo de Michel Bertrand en el que ofrece un anticipo de la investigación que está realizando. A partir de la hipótesis de que los sistemas relacionales son el andamiaje que sostiene todo el sistema social, Bertrand se dedica al estudio de las élites locales de Puebla en los siglos XVII y XVIII. De entrada deja ver algunos planteamientos interesantes. Señala (aunque sin ahondar al respecto) que Puebla es la "verdadera “capital” de los colonos españoles” y que se propone analizar el proceso de construcción de la "criollidad" al responder la pregunta ¿qué es ser criollo en el contexto poblano? Bertrand se propuso lidiar con los problemas de identidad y los abordó mediante un efecto de espejo al confrontar a los actores externos y el proceso que siguieron para integrarse a una sociedad local. Su conclusión, aunque provisional, es que su integración se logra al ingresar en las redes de sociabilidad locales sobre todo por medio del matrimonio y la Secuencia. E-ISSN 2395-8464 
relación de parentesco tío-sobrino por la importancia del componente eclesiástico, de lo que se desprende otra propuesta: en Puebla la rivalidad entre los cabildos civil y eclesiástico no existió, sino que fueron complementarios. Incluso Bertrand termina su ensayo planteando una nueva hipótesis que el proyecto en curso deberá seguir y en su caso comprobar: ${ }_{\mathrm{C}}^{\text {fue el cabildo }}$ catedralicio el más importante por su poder económico?

La tercera y última sección temática titulada "Corporaciones mercantiles y gestión política a fines del periodo colonial” incluye tres ensayos escritos por Javier Kraselsky, Luis Aguirre e Iliana Quintanar.

Kraselsky presenta un trabajo sobre "Las corporaciones mercantiles en el Río de la Plata a fines del siglo XVIII" que es un balance de las investigaciones que ha hecho enfocadas al análisis del sistema político. Especialista en la historia del Consulado de Buenos Aires, ha desarrollado un concepto para explicar el sistema de poder que ha llamado "centralización corporativa”, que cuestiona que el poder monárquico fuera absoluto, adscribiéndose a la propuesta de que se trató de un poder negociado. Esto define la dinámica de poder desarrollado entre los mecanismos de dominación de la Corona y el control local ejercido por las corporaciones mercantiles: el Consulado, la junta de gobierno en Buenos Aires y las diputaciones de Montevideo y Potosí. Como en varios de los otros estudios que componen este volumen, Kraselsky también emprende su análisis desde abajo, con la premisa de que las estructuras globales de la monarquía en América deben comprenderse desde lo local, y reivindica asimismo la importancia de no disociar lo económico de lo político.

Luis Aguirre, autor del segundo ensayo temático de la última sección, estudia el Consulado de comerciantes de Montevideo. Su objetivo fue tratar temáticamente el desenvolvimiento de la institución consular uruguaya y su impacto político en el proceso de independencia. Resulta muy interesante el tema porque se trató de un Consulado situado en Secuencia. E-ISSN 2395-8464 
una región de “frontera”, la rioplatense, donde los uruguayos no sólo tuvieron que enfrentarse a los ingleses y luso-brasileños, sino sobre todo competir con Buenos Aires. Aguirre expone el proceso de fundación del Consulado, la forma en la que administró justicia, sus estados financieros y su interacción con las distintas autoridades gubernamentales con las que le tocó lidiar, pero promete nuevas investigaciones sobre las trayectorias individuales de sus miembros y los costes de negociación de la corporación mediante el análisis de sistemas relacionales.

Este libro cierra con un ensayo de Iliana Quintanar sobre las "Redes mercantiles y de negocios del Consulado de La Habana, siglos XVIII-XIX”. Se pregunta por las implicaciones que tuvo la fundación de la corporación mercantil habanera en la reestructuración de los circuitos mercantiles y las redes de negocios del Caribe en el contexto de los cambios en la política imperial y las guerras finiseculares. Quintanar concluye que el Consulado colaboró en general con el capitán general de la isla y con el ayuntamiento habanero, pero sólo cuando persiguieron el mismo fin, pues muestra también que la corporación no dejó de aprovechar en su beneficio la situación geoestratégica excepcional de La Habana y las oportunidades que se presentaron con los conflictos bélicos.

Este libro es producto de un esfuerzo colectivo que combinó varios proyectos de investigación. El principal fue el encabezado por Antonio Ibarra en México, pero sumó otros coordinados por Fernando Jumar y Javier Kraselsky en Argentina. Es evidente que sí hubo un trabajo colectivo en la medida en la que los doce ensayos comparten planteamientos y métodos, a saber: primero, la reivindicación de los actores sociales individuales y su asociación corporativa, definidos no sólo por su actuar económico, sino sobre todo por su desempeño político y social. Segundo, la combinación de las escalas espaciales a partir de la localidad y su articulación con la esfera global, y tercero: el análisis relacional a partir de descubrir las relaciones interpersonales. Sólo con un esfuerzo así, articulado a nivel internacional, se puede Secuencia. E-ISSN 2395-8464 
avanzar en estas nuevas perspectivas historiográficas. Pero también hay diferencias importantes entre los doce ensayos, pues unos son síntesis y balances de investigaciones realizadas a lo largo de varios años y otros son avances preliminares de investigaciones en proceso, que espero que pronto se concluyan y formen parte de una obra que en su conjunto ofrezca una reflexión madura y reposada. 